\title{
Las relaciones Europa-América Latina: no van por buen camino
}

\section{Fecha de recepción: 29/03/2010 - Aprobación:05/04/2010}

\section{Palabras del expresidente Ernesto Samper Pizano, en el acto de apertura del 11 Foro de Biarritz sobre el Estado de las Relaciones de Europa y América Latina.}

La última Cumbre Europa-América Latina celebrada en la ciudad de Madrid, aunque registró avances importantes en ciertos campos como el de la integración comercial, la cooperación internacional en ciertas aéreas específicas y el manejo regional de la crisis financiera internacional, no mostró avances significativos en áreas de interés crítico para la región latinoamericana como una reglamentación más favorable del problema de los migrantes, una actitud más generosa en el desmonte de los subsidios agrícolas europeos, que hoy obstaculizan el ingreso de los productos latinoamericanos a los mercados blindados europeos o la provisión de mayores recursos europeos para reducir "como lo hizo la UE por medio de fondos de cohesión" las profundas asimetrías sociales y geográficas que caracterizan el hemisferio latinoamericano. Estas verdades reafirman la idea de que las cosas en América Latina van bien, regular en Europa y mal entre los dos hemisferios.

Latinoamérica se ha convertido en un espacio estratégico global por cuenta de sus reservas en bienes globales prioritarios como energía, biodiversidad, alimentos y tierras cultivables; durante la última crisis financiera la región, además, demostró que gracias a las previsiones que tomó para afrontar crisis financieras pasadas, como las de México y Brasil, en esta ocasión pudo tomar, sin mayores contratiempos, las medidas anticíclicas y de regulación que le permitieron sobrellevar el impacto negativo proveniente de la crisis de Europa por medio de la disminución del comercio, la cooperación, los envíos de remesas y la inversión. Esta capacidad de respuesta explica por qué las cifras sobre desempleo no se alteraron de manera significativa y la inflación se mantuvo en sus niveles saludables de un solo dígito.

Este entorno económico favorable viene de hace varios años, cuando la región le apostó a la estabilidad macroeconómica como condición sine qua non para poder sostener unas cifras positivas de crecimiento. Lejos de los tiempos aciagos de las emisiones monetarias populistas, 
Latinoamérica

se ha

convertido

en un espacio

estratégico

global por

cuenta de sus

reservas en

bienes globales

prioritarios

como energía,

biodiversidad,

alimentos

y tierras

cultivables. los sobreendeudamientos irresponsables y las aventuras cambiarias y fiscales, Latinoamérica entendió que sin mantener el barco del desarrollo en equilibrio, este no llegaría a ningún buen puerto. Este compromiso con la estabilidad macroeconómica yla consecución de la gobernabilidad en democracia podrían mencionarse como las dos grandes conquistas latinoamericanas de las últimas décadas del pasado siglo.

\section{Mejorar relaciones de competitividad e inversión}

La región tiene por delante dos desafíos inmediatos: el de la competitividad en lo económico que le permitirá insertarse con mayor o menor ventaja en el proceso actual de globalización y el de la legitimidad para asegurar en el largo plazo su democracia por medio de la reducción de los profundos niveles de desigualdad social que la caracterizan. Las relaciones Europa-América Latina deberían tener por ello como primer objetivo, el mejoramiento de las condiciones de competitividad regional y la profundización de la inclusión social como fuente de legitimidad de sus sistemas políticos.

Los países no son competitivos frente a sí mismos sino frente a los demás; los esfuerzos que realicen para aumentar sus niveles de ahorro, avanzar en la construcción de infraestructura para el desarrollo, mejorar sus niveles de ciencia y tecnología en un mundo que cada vez se divide más entre los que saben y no saben y abrir nuevos espacios de conectividad definirán, al entrar en competencia con otros países, cuál es el puesto que ocupan en el reñido campeonato de la competitividad internacional. El comportamiento reciente de la inversión extranjera europea en las dos últimas décadas ha mostrado ciclos de auge, como el que duró entre los años 1993-1998 cuando las empresas europeas, especialmente las españolas, participaron en el mercado de adquisiciones y fusiones resultantes del auge privatizador de la época y momentos de desánimo como los registrados en estos últimos años como consecuencia del impacto de la crisis financiera internacional sobre los mercados europeos de inversión. Afortunadamente, las empresas europeas que "creyeron" en la capacidad de recuperación de América Latina en los momentos en que esta atravesaba por las dificultades derivadas de las crisis del tequila y la zamba, hoy día están enjugando sus pérdidas europeas con las utilidades latinoamericanas.

El panorama de la inversión, en el largo plazo, puede resultar menos optimista. Los niveles de inversión de hoy, cuando se vive un proceso de apertura económica mundial, están por debajo de los que tenía la inversión extranjera directa en la región en los años 1960 y 1970 cuando existía un modelo de desarrollo proteccionista alérgico a la presencia de capitales extranjeros, especialmente en ciertos sectores estratégicos como el de los servicios públicos y financieros.

El anuncio de la creación de una facilidad para promover la inversión europea en esta parte del mundo con un fondo de 115 millones de euros no pasa de ser simbólico si se contrasta con los 450.000 dólares que necesita la región para construir infraestructura durante los próximos cinco años. Por fortuna, el déficit de los flujos europeos para inversión ha venido siendo reemplazado por el desarrollo importante de un nuevo tipo de inversiones, las "inversiones translatinas" resultantes de la expansión de actividades dentro del área de empre- 
sas de la región como CAF, CEMEx, PDVSA, Petrobrás y Falabella, que han terminado por crear un mercado latinoamericano sursur de bienes, servicios y capitales sobre el cual podría desarrollarse una nueva y más autónoma propuesta de internacionalización de las economías del área.

Los flujos de cooperación internacional europeos, que forman parte de esta intersección económica entre las dos regiones, también han venido cayendo en los últimos años en la medida en que están asignados a países por debajo de niveles de renta media superiores a muchos de los países latinoamericanos. A esta dificultad se añade la atomización de los proyectos cooperantes, diseminados en un $72 \%$ en pequeños destinos puntuales, sometidos a fuertes condicionalidades y sin una agenda clara que los identifique con unas líneas generales de ayuda estratégica. Algunos países, como Suecia y Gran Bretaña, inclusive han dejado saber que ya no considerarán la región como destino para sus proyectos de cooperación; otros, como Italia y aun España han anunciado recortes de fondo para estos programas como parte de sus planes internos de ajuste fiscal.

Los niveles de comercio no han corrido con mejor suerte. A pesar de que, como ya se señalaba, en la Cumbre de Madrid se avanzó en la suscripción de acuerdos de libre comercio con Centroamérica, Perú y Colombia, está claro que, después de varios años, no ha sido posible avanzar en la negociación de importantes acuerdos como el de Mercosur. La decisión de reemplazar acuerdos con regiones por acuerdos con países -como sucedió en Madrid durante su Cumbre en el caso de la Comunidad Andina con los acuerdos bilaterales suscri- tos con Colombia y Perú- ha contribuido a la desarticulación y fragmentación de los precarios procesos de integración latinoamericana; así sucedió cuando el ideal del "gran bloque interamericano" lanzado en 1992 en la Cumbre de las Américas de Miami por el Presidente Clinton terminó convertido en un archipiélago de tratados de libre comercio que, en la práctica, dividieron el hemisferio en dos grandes $y$ diferenciados bloques hacia el sur y hacia el norte de Panamá.

\section{Desigualdades sociales y situación de migrantes}

Como en este caso, las últimas negociaciones de integración de Latinoamérica con la Unión Europea han sido más divisivas que convocantes; en dichos acuerdos, como en los suscritos con Estados Unidos, tampoco se mencionan los temas que le interesan a los países latinoamericanos, como la reducción de las desigualdades sociales -que va más allá del concepto abstracto de la cohesión social promovido por Europa-, la reducción de los subsidios agrícolas, la protección de la biodiversidad amazónica o la regulación no criminal del problema de los migrantes.

El desafío de la legitimidad busca reducir la desigualdad social latinoamericana y reformar al mismo tiempo los mecanismos que, según el último informe del Programa de Naciones Unidas para el Desarrollo, perpetuán y reproducen la asimetría social del continente como la educación y la informalidad de sus mercados de trabajo. Y como no basta con que los gobiernos sean elegidos democráticamente para que sean democráticos, sino que además, como afirma Zobato, se precisa que "gobiernen democráticamente", existen temas relacio- 
La importancia económica de las migraciones está siendo medida a través de las remesas que representan para algunos países latinoamericanos una porción considerable desus exportaciones $y$ su PIB nados con el funcionamiento de la estructura democrática que deben ser examinados. La libertad de prensa es uno de ellos; el examen sobre su estado que se hace en este Foro debe partir, por supuesto, de la protección del derecho a la vida y al trabajo de los periodistas, y considerar problemas capitales como la censura de prensa pero también debe abarcar otros fenómenos como la concentración mediática y la peligrosa confusión entre el legítimo interés particular de los propietarios de los medios y el interés público de la información que suministran a los ciudadanos.

La implicación más directa de la relación interoceánica con esta búsqueda de la legitimidad tiene que ver con el tratamiento de los casi cinco millones de migrantes latinoamericanos en Europa; 26 millones de migrantes latinoamericanos se encuentran amenazados por este nuevo sesgo antimigracionista que atraviesa el mundo y que está llegando a comportamientos xenofóbicos y racistas, de los cuales no escapa la Europa de hoy, en actitud muy distinta a la Europa que defendía los derechos humanos hace un par de siglos y que inspiraron la base moral de nuestra Independencia.

El trato que ellos están recibiendo en Europa hoy está más encaminado hacia la criminalización que a la regulación de su presencia y permanencia en territorio europeo. Así lo demuestran evidencias tan contundentes como los muros físicos que hoy dividen Estados Unidos y México o Israel y Palestina, como la imposición de restricciones a la movilidad de migrantes establecida recientemente por Francia para la población gitana y los recortes a sus derechos electorales en Italia. La nuez del conflicto sigue estando en la Directiva del
Retorno que se ha convertido en un verdadero “Guantánamo europeo”, en relación con los derechos de los migrantes ilegales al negarles el debido proceso, propiciar la desintegración de sus familias y establecer normas de internamiento para su expulsión incompatibles con las normas universales que regulan el derecho al debido proceso.

El tema es más complejo si se mira dentro del marco más amplio de la globalización. ¿Cuál es la razón para defender a capa y espada la libre circulación de capitales, bienes, servicios, tecnologías e impedir, al mismo tiempo, la movilidad del trabajo que les interesa a los países en desarrollo como la mayoría de los que integran Latinoamérica? Ese es el verdadero dilema ético de una globalización que divide el mundo entre ricos y pobres, conectados $y$ desconectados, ganadores y perdedores.

Cuando hablamos del trabajo calificado las cosas son distintas; este tipo de mano de obra constituye en la práctica una forma de apropiación, por parte de los países de acogida del migrante preparado, de la inversión educativa realizada por los países de origen; muchos de los profesionales latinoamericanos están llegando a colocarse en actividades para las cuales no se requieren sus niveles actuales de preparación produciendo, según la Organización Internacional para las Migraciones, un fenómeno de “descalificación” laboral que fomenta el subempleo y el empleo poco digno.

La importancia económica de las migraciones está siendo medida a través de las remesas que representan para algunos países latinoamericanos una porción considerable de sus exportaciones y su PIB; las discusiones suscitadas por entidades como 
el Fondo Monetario Internacional sobre el “impacto no productivo" de estos fondos son propias de un neoliberalismo decadente; el efecto de estas remisiones monetarias, sobre la estructura de producción es exactamente el mismo que tiene la generación de un puesto de trabajo en el país de origen respecto al impulso de la demanda y a través de ella, en el sector productivo de bienes y servicios.

Hasta que Europa no entienda que el problema de las migraciones tiene que ver con los derechos humanos que regulan la igualdad en las condiciones de contratación de trabajadores extranjeros o nacionales, aseguran el reintegro de las familias migrantes y fundamentan éticamente las regularizaciones masivas de los migrantes existentes, el tema seguirá siendo motivo de conflictos y controversias con Latinoamérica.

\section{Hacia una nueva alianza estratégica birregional}

Si América Latina va en términos generales bien, Europa no va por el mismo camino. La reciente crisis financiera demostró que el éxito económico de la unión había impedido ver su fragmentación política (Moran). Francia se ha dedicado a producir ideas para que las pague Alemania y esta todavía ejerce de manera vergonzante su condición de primera potencia de Europa. Como en las más ilustres herencias, cuando el reparto saca a flote pasiones ocultas de la familia, la crisis económica reciente mostró las distancias políticas que separan a los socios de la Unión.

América Latina no está, definitivamente, en los primeros lugares de la agenda de prioridades de la nueva política externa; asuntos como la ampliación del espacio euro- peo, la nueva constitución, la inclusión de Turquía, el nuevo relacionamiento con la OTAN, la manera de abordar los problemas del Mediterráneo y conducir el nuevo relacionamiento con la China, están, legítimamente, por encima de preocupaciones como las relaciones con América Latina. La Unión Europea no sabe qué hacer con América Latina y ésta no sabe cómo comportarse frente a Europa. Entre las dos regiones existe, como bien dice Couffignal, un desarme recíproco que nace de una desilusión compartida. Este desencuentro parece confirmarse en hechos como la desaparición de la región en el nuevo organigrama de Bruselas; los intereses latinoamericanos se tramitan hoy por medio de una Oficina de Misceláneos donde se mezclan intereses de distintos países y orígenes; la presencia española en Bruselas que hasta hace algunos años era muy fuerte-por medio de comisarios como Manuel Marín y el canciller Javier Solana- se ha venido debilitando y con ella, la preocupación europea por la región. La señora Ashton, flamante canciller de Europa, se tardó varios meses en visitar Haití después de la tragedia del terremoto; cuando lo hizo, le pasó algo parecido a Cristóbal Colón, que cuando salió del viejo continente no sabía para dónde iba y cuando llegó a América no tenía ni idea en donde estaba. Al paso que llevan las relaciones entre las dos regiones no es improbable que volvamos a caer en la simplificación fetichista del pasado cuando los europeos confundían América Latina con la boina del Ché y los latinoamericanos a Europa con la cruz gamada de Hitler.

Hacia el futuro habría que pensar en el diseño de una nueva "alianza estratégica birregional”, que debería partir de una agenda concreta de temas que incluya, por 
Así como no existe una América sino "varias américas" distintas, también existen "varias europas", comose ha visto a raíz de la reciente crisis financiera internacional. supuesto, preocupaciones globales comunes como el multilateralismo, los derechos humanos y el manejo climático, pero al lado de otros temas contenciosos como la integración de los migrantes, la protección de la inversión europea en América, la reducción de los subsidios agrícolas o el reconocimiento de la biodiversidad amazónica. Nuestro triste destino no puede ser, parafraseando a Neruda que "para que nada nos divida que nada nos una".

Para que dicha agenda no se convierta en una declaración retórica de buenas intenciones, debería venir acompañada de mayores recursos de cooperación, inversión y posibilidades de comercio que hoy día, como se demostró, se encuentran deprimidos. Sería una agenda que combine intereses y valores, que en el mundo de hoy no son excluyentes sino complementarios y necesarios. Se trataría de llegar a una nueva agenda política que debe estar acompañada con unos propósitos económicos definidos en materia de cooperación, inversión y comercio.

La agenda interregional actuaría como una nueva Alianza Interatlántica, parecida a la que se está formando en el Pacífico. En esta búsqueda, las dos regiones tendrían que contar con los Estados Unidos; el presidente Obama ha hablado de un nuevo amanecer en las relaciones de su país con América Latina, que incluirían la ampliación de la agenda vigente concentrada, desde hace muchos años, en el narcotráfico, el terrorismo y el libre comercio. La inclusión de otros temas, compatibles con los que se compartirían con Europa, como el desarrollo de nuevas energías, el fortalecimiento de la gobernabilidad democrática, la regularización de los migrantes ilegales, la aplicación de los derechos humanos o la terminación de la base de Guantánamo en Cuba, formarían parte de esta esperanzadora propuesta que, infortunadamente, no se concreta todavía.

El éxito de la propuesta depende de la capacidad que tenga el gobierno de Washington de entender que la realidad de la región es mucho más compleja de lo que parece, que no se puede dividir, simplistamente, entre países "chavistas" y "no chavistas", cuando lo que existe es un proceso en curso de formación de dos modelos ideológicos de desarrollo, identificados en la necesidad de avanzar en la solución del grave problema de exclusión social, sí, pero apoyados en concepciones distintas sobre el papel del Estado, la función social de la propiedad privada y el papel de la democracia.

Así como resulta útil pensar en los beneficios de repolitizar las relaciones internacionales de Latinoamérica por medio de la creación de nuevos escenarios, como Unasur, en los cuales los dirigentes latinoamericanos puedan ventilar y solucionar abiertamente sus diferencias políticas, la región cometería un suicidio histórico al “ideologizar" su política externa, como lo pretenden dirigentes como Alan García, subordinándola a una discriminación ideológica, que reviviría en la región las épocas aciagas de la Guerra Fría cuando los países supeditaban la existencia de sus relaciones a identidades de ideología.

Así como no existe una América sino "varias américas" distintas, también existen "varias europas", como se ha visto a raíz de la reciente crisis financiera internacional; Estados Unidos, por su parte, es una realidad mucho más compleja que la Casa Blanca y el Pentágono, como se demostró 
con la ocurrencia del reciente referendo para la legalización de la marihuana en California que, a pesar de no resultar aprobado, deslegitimó la política de lucha contra las drogas adelantada por Estados Unidos en el mundo.

Muy cerca de esta ciudad emblemática de Biarritz, a menos de cinco kilómetros de distancia, en la ciudad de Bayona, se decidió la Independencia de América. En Bayona, Napoleón forzó la dimisión de Fernando VII a favor de su padre Carlos IV quien, a su turnó, cedió la corona a José Bonaparte, hermano del Emperador. El Rey depuesto, con toda su Corte, quedó prácticamente preso en un inhóspito Castillo del cual sobreviven unas pocas paredes luego de un devastador incendio. La invasión napoleónica de la Península Ibérica sucintó una intensa ola de rechazos que se concretó en la creación de múltiples Juntas de Gobierno provinciales que, invocando la soberanía del pueblo, declaraban su lealtad al Rey y el rechazo al gobernante intruso. Las provincias americanas, por convicción o por estrategia, encontraron en las juntas soberanistas españolas la oportunidad de empezar a marcar distancias con Europa sin romper con la monarquía.

El autonomismo de comienzos del siglo XIX se convertiría, con los movimientos revolucionarios de los finales del siglo XVIII, como el de los comuneros en Colombia, en el primer paso hacia la Independencia. Esta ultima fue el resultado de varios procesos distintos: el mexicano inspirado por
Hidalgo y Morelos, tumultuoso, revolucionario, desorganizado; el centroamericano, formal, notarial, cristalizado a través de la expedición de actas emancipadoras y el suramericano, inspirado por Bolívar y San Martín concentrado en la guerra.

Mientras tanto, los cuadros leales al Rey se refugiaban en la ciudad de Cádiz y tendían, a través de la expedición de una nueva Constitución, una mano a las provincias de ultramar para invitarlas a formar parte, con una representación minoritaria, de unas nuevas Cortes iberoamericanas que, de haber prosperado, hubieran dado lugar al nacimiento de una asociación interregional estratégica parecida a la mancomunidad británica.

Fernando VII no valoró el apoyo ni la lealtad recibida por sus antiguas colonias y prefirió enviar una expedición militar de reconquista liderada por el general Pablo Morillo, quien había derrotado a las fuerzas napoleónicas de invasión, al frente de más de 15.000 hombres.

Solo hasta entonces supieron en América que Bolívar tenia razón: que la Independencia no sería posible sin el derramamiento de sangre patriota; solo entonces comenzaría el verdadero proceso emancipatorio americano que, al final, le dio la posibilidad a Bolívar de derrotar, por intermedio de Morillo, a Napoleón, el personaje que más admiraba por sus hazañas militares y más le había desilusionado por sus veleidades monárquicas.

Biarritz, noviembre 4 de 2010 